\title{
Influence of Superimposed Vibrational Load on Dwell Time Crack Growth in a Ni-Based Superalloy
}

Erik Storgärds, Jonas Saarimäki, Kjell Simonsson, Sören Sjöström, Tomas Månsson and Johan Moverare

\section{Linköping University Post Print}

\section{Tweet}

N.B.: When citing this work, cite the original article.

Original Publication:

Erik Storgärds, Jonas Saarimäki, Kjell Simonsson, Sören Sjöström, Tomas Månsson and Johan Moverare, Influence of Superimposed Vibrational Load on Dwell Time Crack Growth in a NiBased Superalloy, 2016, International Journal of Fatigue, (87), 301-310.

http://dx.doi.org/10.1016/j.ijfatigue.2016.02.018

Copyright: Elsevier

\section{http://www.elsevier.com/}

Postprint available at: Linköping University Electronic Press

http://urn.kb.se/resolve?urn=urn:nbn:se:liu:diva-126921

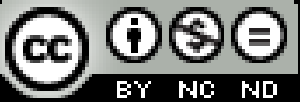




\title{
Influence of superimposed vibrational load on dwell time crack growth in a Ni-based superalloy
}

\author{
Erik Storgärds $^{*}$, a Jonas Saarimäki ${ }^{\mathrm{b}}$, Kjell Simonsson ${ }^{\mathrm{a}}$, Sören Sjöström ${ }^{\mathrm{a}}$, Tomas \\ Månsson $^{\mathrm{c}}$, Johan Moverare ${ }^{\mathrm{b}}$ \\ ${ }^{a}$ Division of Solid Mechanics, Linköping University, SE-58183 Linköping, Sweden \\ ${ }^{b}$ Division of Engineering Materials, Linköping University, SE-58183 Linköping, Sweden \\ ${ }^{c}$ GKN Aerospace Engine Systems, SE-46181 Trollhättan, Sweden
}

\begin{abstract}
Sustained loads have for some Ni-based superalloys been shown to give rise to increased crack growth rate at elevated temperature. Such loads generate a history dependent fatigue problem due to weakening and cracking of grain boundaries during dwell times, later broken apart during subsequent load cycles. So far most studies have focused on the interaction of load cycles, overloads, and temperature. However, vibrations of different kinds are to some extent always present in engine components, and an investigation of how such loads affect the dwell time cracking, and how to incorporate them in a modelling context, is therefore of importance. In this paper a study of the most frequently used gas turbine material, Inconel 718, has been carried out. Mechanical crack propagation testing has been conducted at $550^{\circ} \mathrm{C}$ for surface cracks with and without the interaction of superimposed vibrational loads. Subsequent investigation of the fracture behaviour was performed by scanning electron microscopy and the modelling work has been conducted by incorporating the vibration load description within a history dependent crack growth law. The obtained results show reasonable
\end{abstract}

\footnotetext{
* Corresponding author. Tel.: +46 (0)13282475.

E-mail address: erik. storgards@liu.se (E. Storgärds).
} 
accuracy with respect to the mechanical test results.

Keywords: Dwell times, vibrational load, Crack growth modelling, Inconel 718, High temperature

\section{Introduction}

Crack growth in Ni-based superalloys at elevated temperature has been seen to be heavily influenced by the load mode the material it is subjected to. Depending on the loading frequency, a significant difference can be seen in the crack growth behaviour. For more rapid cyclic loading, transgranular growth is dominating (as for most other metallic materials). However, this is not the case for lower frequencies (i.e. dwell times) and sustained loads, which have been seen to cause intergranular crack growth, see e.g. [1]. The latter situation has also been shown to give rise to an increased growth rate per load cycle, see e.g., [2] where examples of this can be found for Inconel 718. Several other studies over the past decades have also shown the same phenomenon for different temperatures and alloy compositions, see e.g. [3-12].

Much resources have been put into investigating the reason behind this dwell time effect, but a complete description of the damage process has still not been found. A number of theories have been developed, the two most commonly referred to being dynamic embrittlement (DE), see [1], and stress accelerated grain boundary oxidation (SAGBO), see [13]. Models for describing the damage are either physically based ones, where an actual damage mechanism is described in order to handle the crack growth behaviour, such as in [14], or of a more phenomenological nature e.g. [15-17]. A third type has also been seen which combines the two (physical and phenomenological) for describing the history dependence. Examples of this can be found in $[18,19]$ which partially use input 
from FE simulations and in $[2,20]$ which are solely based on LEFM.

Studies of other load types than dwell time at max load have not been frequently seen. Some works have focused on overloads in combination with dwell times, see e.g. [5, 21-25], load spectra with dwell times, see e.g. [20, 26, 27], and thermo-mechanical crack growth with dwell times, see e.g. [19, 28-31]. Few studies have focused on one of the most common situations in an engine environment, namely how vibrations affect the dwell time crack growth. Such loads are present in the daily operating environment of land-based gas turbines as well as aero engines, and have been shown to be a cause of fatigue and component failure. How they affect the crack growth during dwell times (or sustained load) in a high temperature environment is, however, relatively unknown.

Crack growth under vibrational load at elevated temperature has been studied in e.g. [32] for Inconel 718 and in [33] for the Ni-based single crystal alloy PWA 1484. Both showed elevated crack growth for a superimposed vibrational load on the dwell time load. Limited to only these few experimental studies, there is a need for more investigations regarding how the growth mechanism, e.g. the intergranular/transgranular relation, depends on the vibrational load, and of how to model the vibration and dwell time interaction.

To contribute to this important, but still relatively unknown subject, an investigation of how the Ni-based superalloy, Inconel 718, is affected by superimposed vibrational loads on dwell times is reported in this paper. Mechanical crack propagation experiments for various loading conditions with and without vibrational loads, the latter for comparison reasons, have been conducted at $550^{\circ} \mathrm{C}$. Following these experiments an investigation of the crack paths by scanning electron microscopy to investigate the crack growth mechanism was performed. Further, the effect of vibrational loading on dwell times has been modelled by using the 
physically motivated phenomenological history dependent LEFM crack growth model presented in $[2,20,27,31,34]$.

\section{Experiments}

\subsection{Method}

Fatigue crack growth tests were performed in load control, at $550^{\circ} \mathrm{C}$ on $\mathrm{Kb}$ type (surface crack) specimens (rectangular cross section of $4.3 \times 10.2 \mathrm{~mm}$ ) of Inconel 718 (bar material), heat treated according to AMS 5663 standard, with an approximate grain size of $10 \mu \mathrm{m}$. To achieve a constant and stable temperature throughout the test a resistance furnace with 3 heating zones and thermocouples in contact with the specimen was used. The initial notch was created by electro discharge machining (EDM), and the subsequent pre-cracking was done at room temperature using a $10 \mathrm{~Hz}$ sine load with $\sigma_{\max }=650 \mathrm{MPa}$ and $R_{\sigma}=0.05$ according to ASTM E647 [35]. Crack growth was monitored by direct current potential drop (DCPD), while the subsequent stress intensity factor (SIF) evaluation was done by assuming a semi-circular crack front [36]. In all tests the point of consideration was the deepest point of the crack geometry, for which the cracked area was evaluated through a pre-defined calibration curve based on temperature induced beach marks under a cyclic load of $0.5 \mathrm{~Hz}$ for which post mortem measurements of crack length and PD values were correlated with each other.

\subsubsection{Evaluation procedure}

The use of a pre-defined calibration curve based on cyclic loading has been proven to be an effective method for evaluating the effect of material damage (weakening and embrittling of grain boundaries) caused by dwell times, here 
denoted damaged zone. Comparison between some different evaluation methods can be found in e.g. [12], where it was shown that the one used in this paper is beneficial for dwell time crack growth.

\subsection{Tests}

Several test types were chosen to investigate the vibrational load interaction on dwell time crack growth, where information regarding the crack growth on a microstructural scale, and growth rates for model calibration, were to be gained. The first test type consisted of a dwell time without any load reversals, i.e. sustained load, while the second one consisted of an identical sustained load with a superimposed vibrational load of constant amplitude and a frequency of 10 Hz. For these tests, centered around the same mean stress value of $650 \mathrm{MPa}$, a fixed $\Delta K$ value was chosen for a crack length of $2.5 \mathrm{~mm}$ (i.e. close to the end of the test), defining the constant $R_{\sigma}$ value used throughout the tests. These were chosen to be at three levels, namely, $\Delta K=1,3$ and $5 \mathrm{MPa} \sqrt{\mathrm{m}}$. Next, a $2160 \mathrm{~s}$ (1/10 of a transatlantic flight of $6 \mathrm{~h})$ dwell time test was used to see the influence of larger load reversals; here a $R_{\sigma}=0.05$ load reversal was applied between each cycle. Fourthly, the same 2160 s test type was used but with a superimposed vibrational load, here only 1 test of $\Delta K 3 \mathrm{MPa} \sqrt{\mathrm{m}}$ was performed. The load reversal frequency for the major load cycles in the latter 2 test types was set to $0.5 \mathrm{~Hz}$, while a load frequency of $10 \mathrm{~Hz}$ was used for the vibration load.

The next test type was developed in order to gain information of how the material damage is affected by a larger cyclic load with $R_{\sigma}=0.05$. This test type, denoted mixed test, was initiated by a cyclic block followed by a sustained load block, and finally ended by a cyclic block. The crack lengths for when to switch block type were chosen based on experience; a more detail description about this 
test type can be found in [2]. A similar mixed test type was then developed to see the influence of vibrational load, e.g. the effect on the damaged zone length. This type was set up in the same way, except for the first cyclic block which was removed. On the sustained load a vibrational load was added (as previously described), here also with $\Delta K=3 \mathrm{MPa} \sqrt{\mathrm{m}}$ to give a good comparison with the rest of the tests. Finally 1 cyclic test with $R_{\sigma}=0.05$ and a load frequency of $0.5 \mathrm{~Hz}$ was performed.

The different test types are illustrated in Fig. 1, while all tests are summarised in Table 1. All test specimens originate from the same batch. Worth noting is, that in [25] a study was carried out showing the influence of scatter in dwell time and cyclic loading, which showed substantial scatter between batches with respect to dwell time effects. For cyclic loads on the other hand, almost no scatter between batches was found. Please note that the scatter was seen as a difference in appearance between the crack growth rates vs. SIF, and that dwell time damage was present in all tests, see also [37].

\section{Experimental results}

\subsection{Dwell times with vibrational load}

Results from the dwell time tests containing a superimposed vibrational load, i.e. tests 03, 04, 05 and the first part of test 09, are seen in Fig. 2. An initial transient was present in the beginning of each test, followed by a steady state growth until (except for test 03 with $R=0.975$ ) the crack growth increased when closing in on the final crack length. This behaviour is not unusual for fatigue tests in general, what differs from these is that the crack growth initiates from $\Delta K$ levels as low as $0.4 \mathrm{MPa} \sqrt{\mathrm{m}}$, indicating the presence of dwell time damage from the beginning. A cyclic growth seems unlikely at these low $\Delta K$ values. More 
likely is that a $\Delta K_{\text {th }}$ value for cyclic crack growth to occur is located somewhere between $1 \mathrm{MPa} \sqrt{\mathrm{m}}$ (where test 03 ends) and $2.5 \mathrm{MPa} \sqrt{\mathrm{m}}$ where the increased crack growth rate for test 04 was seen. The motivation for the cyclic threshold value is given in Section 3.2.

\subsubsection{Incubation time}

An incubation time was observed before the steady state crack growth commences, which also implies that the test started by a "dwell time" growth. The incubation time behaviour related to dwell time crack growth has been studied previously, see e.g. $[2,25,38]$, where it was found to most likely be related to the orientation of the crack through the grain boundaries when they begin to crack.

\subsection{Effect on the damaged zone due to vibrational load}

The mixed tests were used to investigate the effect of vibrational load on dwell time cracking and in what way the damaged zone is affected. An evaluation of the length of the damaged zone for the mixed tests with and without vibrational load is seen in Fig. 3, where tests 08 and 09 are compared with test 10 (cyclic test) for baseline data. It is seen that the damaged zone was reduced from its original value of $0.5 \mathrm{~mm}$ for the dwell time test to $0.3 \mathrm{~mm}$ for the dwell time test with superimposed vibrational load, thus indicating that the growth of the damaged zone to some extent was restricted by the vibration cycles. Consequently, the cyclic threshold value must have been overcome in order for the cyclic crack growth to occur, where it in addition most likely is larger than the $0.4 \mathrm{MPa} \sqrt{\mathrm{m}}$ for test 04 as discussed previously.

Measurements of the damaged zone length have been conducted in many other studies, and has been shown to depend on temperature and plane stress/strain state. In [12] it was observed that heavy tunneling was present, indicating that 
plane stress (reduced constraint) reduced the damaged zone length during the sustained load tests. The equivalent stabilised length of $0.5 \mathrm{~mm}$ was in similar studies, e.g. [2], shown to be valid for $550^{\circ} \mathrm{C}$ and the triaxial stress state found in a Kb-specimen.

\subsection{Dwell time crack growth rate}

The crack growth rates for the dwell time tests without any vibrational load are shown in Fig. 4 together with the dwell time tests including vibrational load and the dwell time part of the mixed tests (with and without vibrational load). As can be seen, the maximum crack growth rate of all tests, was the level set by the pure sustained load tests. For the $2160 \mathrm{~s}$ tests it was noted that the major load reversals reduced the growth rate, as the crack needs to re-orient through the grain boundaries and sharpen itself from crack tip blunting after it has been subjected to a load reversal significantly larger than that of the superimposed vibration cycles, see also [24, 25]. Note that for the $2160 \mathrm{~s}$ tests the crack growth rate is represented by 1 load cycle, i.e. the ramp-up, dwell time and ramp-down.

\section{Microscopy}

A Hitachi SU70 FEG analytical scanning electron microscope (SEM), operating at $1.5-20 \mathrm{keV}$, was used together with Electron Channelling Contrast Imaging (ECCI) [39] to get high quality, high contrast pictures of the typical microstructure.

When looking at the crack path of the four tests 03, 04, 05, and 07 in Fig. 5, some similarities can be seen. In general all samples show intergranular crack growth. Figs. 5a, b and d show more severe plastic deformation, than in Fig. $5 \mathrm{c}$. What is also notable is how the crack branch lengths seem to increase when 
the load ratio $R$ is increased. This could mean that tests 03 and 04 with the longer crack branches result in more dwell time damage and as the $R$ value is decreased as in test 05 the damage would be more cyclic. Even though the tests show different cracking and damage mechanisms, they might give the same total damage, i.e. result in the same crack growth rate as seen in Fig. 4.

When looking at the different crack tips a change in crack growth can clearly be seen in Fig. 6, where Fig. 6d shows a quite sharp crack tip of test 07 (the 2160 $\mathrm{s}$ test with a vibrational load ratio of $R=0.93$ ). That crack tip's lightly pinched look could be the effect of a load cycle. In Fig. 6a the dwell time test with a load ratio of $R=0.975$ shows some similar behaviour, but when looking at the dwell time test with a vibrational load ratio of $R=0.93$ in Fig. 6b, a more serrated crack growth can be seen. More importantly, a transition in crack appearance can be seen as the crack tip starts to show blunting. The blunting phenomenon is clearly shown in Fig. 6c, where the crack tip of test 05, the dwell time test with a load ratio of $R=0.88$, is shown. A significant difference can be seen in the microstructure between Figs. 6a, b, d and c, where Fig. 6c shows much more signs of plastic deformation, such as slip bands.

\section{Modelling}

By describing the build-up and consumption of the damaged zone, a history dependent crack growth law can be set up. In [2, 20, 27, 31, 34] the concept has been used for various types of loadings, from simplified start and stop cycles to complicated engine spectra. The model is built around scale factors dependent on the damaged zone, increasing the crack growth rate when the damaged zone is large and likewise reducing it when the damaged zone is small. The use of LEFM makes the model applicable for most industrial applications and for incorporation 
of most load types and situations as the only parameter that has to be tracked through the load history is the length of the damaged zone, denoted $D$.

The model predicts the highest crack growth rates when reaching the stabilised damaged zone length corresponding to the current triaxial state, which can be seen when the $\mathrm{d} a / \mathrm{d} t$ vs. $K_{\max }$ curve reaches a linear trend line [2]. Subsequent consumption of the damaged zone, when e.g. a cyclic load is applied, also increases the crack growth rate (with respect to baseline conditions). In short, the time dependent growth rate takes the form, $\dot{a}_{\mathrm{t}}=f\left(C_{0 \mathrm{t}}, n_{\mathrm{t}}, B_{\mathrm{t}}, D, D_{\max }, K_{\max }\right)$, where $B_{\mathrm{t}}$ is a fitting parameter and where $D_{\max }$ is the damaged zone length at stabilised conditions. The parameters $C_{0 \mathrm{t}}$ and $n_{\mathrm{t}}$ are the stabilised power law parameters for dwell time crack growth. For sustained loading conditions, the damaged zone will grow in front of the crack tip, and the growth rate increases until the value of $D_{\max }$ is reached, cf. [2,34]. The cyclic crack growth rate takes the form, $\dot{a}_{\mathrm{c}}=f\left(C_{\mathrm{c}}, n_{\mathrm{c}}, A_{\mathrm{c}}, B_{\mathrm{c}}, D, D_{\max }, \Delta K\right)$, where $A_{\mathrm{c}}$ and $B_{\mathrm{c}}$ are fitting parameters, while $C_{\mathrm{c}}$ and $n_{\mathrm{c}}$ represent the baseline parameters for cyclic growth.

\subsection{Influence of vibrational loads}

Some different approaches for what growth type to apply, time dependent and/or cyclic, have been developed; in [2] only simplified start and stop cycles were studied which gave very specified cases when to use what type of crack growth type. Typical cycles such as a sustained load interrupted by one or several rapid load reversals were simulated. In [20] more complex engine spectra were analysed and simulated, where it was argued that the highest crack growth rate of the two (dwell time or cyclic load) should contribute to the overall crack advancement. One example is a slowly applied load ramp, which may be handled by a time dependent description, as it is distributed over a long period of time. 
However, having a dwell time and a cyclic load (in this case superimposed vibration cycles) active at the same time requires other ways of describing the damage and crack evolution.

\subsubsection{Interaction function}

Based on the experimental results, it may be concluded that the effect of the sustained load and the superimposed vibrational load must be handled simultaneously, as e.g. a linear superposition model, where the effects of the load types are added together. In detail, a concept is proposed where the vibration load ratio, denoted $R_{\text {vib. }}$, see Eq. (1), is to be used for the interaction between dwell time and cyclic damage.

$$
R_{\mathrm{vib} .}=\frac{K_{\min }^{\mathrm{vib}}}{K_{\max }^{\mathrm{vib}}}
$$

In Eq. (1), $K_{\max }^{\mathrm{vib}}$ is the maximum SIF from the mean value of the dwell time load, and $K_{\mathrm{min}}^{\mathrm{vib}}$ is the corresponding minimum SIF value, see also Fig. 7.

Finally, to realise the $R_{\mathrm{vib}}$. expression in the total crack growth description it is proposed that the total crack growth rate should be applied as seen in Eq. (2). This expression gives a total crack growth rate with a major part due to dwell time growth (as it is applied as sustained load) and a cyclic growth depending on the vibration load ratio.

$$
\dot{a}_{\mathrm{t} \text { tot. }}=\dot{a}_{\mathrm{t}} \times R_{\mathrm{vib} .}+\dot{a}_{\mathrm{c}} \times\left(1-R_{\mathrm{vib} .}\right)
$$

It is to be noted that the expression in Eq. (2) is only valid for the dwell time part of a cycle and only to a certain extent of vibrational load. As an example: 
if $R_{\text {vib. }}$ reaches beyond a few percent it should no longer be considered to be a vibrational load on a dwell time but rather a load cycle by itself. To be more precise, a vibrational load should be seen as a flutter on an engine spectra, e.g. representing disturbances.

\subsection{Cyclic crack growth threshold}

By studying the crack growth rate for the lowest SIF values in Fig. 2, and noting the high load ratios, it was motivated in Section 3 that a cyclic threshold value must be present, denoted $\Delta K_{\text {th }}$. The threshold value should be the same for all tests at the temperature tested, i.e. $550^{\circ} \mathrm{C}$. To include this in the modelling work an industrially recognised expression was applied, namely the one in NASGRO [40], $\left(1-\Delta K_{\mathrm{th}} / \Delta K\right)^{p}$ see Eq. (3). This threshold value is assumed to only depend on the material's, resistance to withstand crack growth at $550^{\circ} \mathrm{C}$.

$$
\frac{\mathrm{d} a_{\mathrm{c}}}{\mathrm{d} N}=C_{\mathrm{c}} \Delta K^{n_{\mathrm{c}}}\left(1-\frac{\Delta K_{\mathrm{th}}}{\Delta K}\right)^{p}
$$

\subsection{Modules}

The damaged zone size $D$ is the history variable that controls the crack growth rate. With the expression developed for considering the vibrational loads, the threshold value expression and the modelling concept in [20], a tool for solving the dwell time interactions with the vibrational load is at hand. Below the details of the rest of the components are given in order for completing the model.

\subsubsection{Plastically induced crack closure}

The dwell time tests with superimposed vibrations should have a very small amount of plastically induced crack closure. The other tests include load reversals at $R=0.05$, which makes it necessary to include a crack closure function. Here 
the one by Newman [41] was chosen, see Eq. (4), where $\alpha$ is a constraint parameter, $\sigma_{0}$ the flow stress, and $c$ a superscript denoting a cyclic load value.

$$
\begin{aligned}
& f=\left\{\begin{array}{lc}
\max \left(R, A_{0}+A_{1} R+A_{2} R^{2}+A_{3} R^{3}\right) & R \geq 0 \\
A_{0}+A_{1} R & -2 \leq R<0
\end{array}\right. \\
& A_{0}=\left(0.825-0.34 \alpha+0.05 \alpha^{2}\right)\left[\cos \left(\pi \sigma_{\max }^{c} / 2 \sigma_{0}\right)\right]^{1 / \alpha} \\
& A_{1}=(0.415-0.071 \alpha) \sigma_{\max }^{\mathrm{c}} / \sigma_{0} \\
& A_{2}=1-A_{0}-A_{1}-A_{3} \\
& A_{3}=2 A_{0}+A_{1}-1 \\
& \Delta K_{\text {eff. }}=\frac{1-f}{1-R} \Delta K
\end{aligned}
$$

\subsubsection{Time dependent crack growth}

A time dependent crack growth function with a growth rate based on the damaged zone is seen in Eq. (5), c.f. [20]. Maximum crack growth rate is received as the damaged zone, $D$, approaches the asymptotic value of $D_{\max }$.

$$
\begin{aligned}
& \dot{a}_{\mathrm{t}}=\frac{D}{D_{\max }} \times C_{\mathrm{t}} K_{\max }^{n_{\mathrm{t}}} \\
& C_{\mathrm{t}}=C_{0 \mathrm{t}}\left(1-\exp \left(\frac{-B_{\mathrm{t}}}{1-\frac{D}{D_{\max }}}\right)\right) \quad B_{\mathrm{t}} \geq 0
\end{aligned}
$$

\subsubsection{Cyclic crack growth}

Cyclic crack growth is also affected by the damaged zone, see e.g. Fig. 3, in which a large damaged zone contributes to a high crack growth rate. An expression for the cyclic crack growth is seen in Eq. (6) where the rate decreases rapidly with decreasing damaged zone length. The "cyclic time" denotes the time 
for a load cycle to complete.

$$
\begin{aligned}
& \dot{a}_{\mathrm{c}}=\frac{1}{\text { cycle time }} \times S_{\mathrm{c}} C_{\mathrm{c}} \Delta K_{\text {eff. }}^{n_{\mathrm{c}}}\left(1-\frac{\Delta K_{\mathrm{th}}}{\Delta K}\right)^{p} \\
& S_{\mathrm{c}}=1+A_{\mathrm{c}}\left(\frac{D}{D_{\max }}\right)^{B_{\mathrm{c}}} \quad A_{\mathrm{c}}, B_{\mathrm{c}} \geq 0
\end{aligned}
$$

\subsubsection{Total crack growth rate}

Based on the suggestion from [20] regarding time and cycle dependent crack advancement, it is proposed that the same should be used when having the superimposed vibrational loads during a dwell time, thus letting the largest one control the crack growth. As the dwell time and the vibrational load interact by the function in $\dot{a}_{\mathrm{t}}$ tot, see Eq. (2), and the cyclic damage by $\dot{a}_{\mathrm{c}}$, see Eq. (6), controls large load reversals (loads which cannot be considered as flutter from engine vibrations, i.e. in this paper everything below $R=0.88$ ), the following crack growth advancement rule is found, see Eq. (7).

$$
\dot{a}=\left\{\begin{array}{lrl}
\dot{a}_{\mathrm{t}} \text { tot. } & \dot{a}_{\mathrm{t} \text { tot. }}>\dot{a}_{\mathrm{c}} \\
\dot{a}_{\mathrm{c}} & \dot{a}_{\mathrm{c}}>\dot{a}_{\mathrm{t} \text { tot. }}
\end{array}\right.
$$

\subsubsection{Damaged zone evolution}

For the evolution of the damaged zone it is proposed that a mechanism-based growth rate, $\dot{m}$, allows for a damaged zone to build-up, while the crack growth rate, $\dot{a}$ in Eq. (7), either slows the build up or completely consumes it. In Eq. (8) the described concept can be seen. For a more detailed description of this function and the other modules in this model see references [2, 20, 27, 31, 34].

$$
\begin{aligned}
& \dot{D}=\dot{m}-\dot{a} \\
& \dot{m}=C_{\mathrm{t}} K_{\max }^{n_{\mathrm{t}}}
\end{aligned}
$$




\subsection{Calibration}

A combined optimisation of tests 01,02 and 08 (i.e. the dwell time parts) was used for determining the parameters $C_{0 \mathrm{t}}, n_{\mathrm{t}}$ and $B_{\mathrm{t}}$. Test 08 was used to determine $D_{\max }$ as seen in Fig. 3. Test 08 and 10 were used for determining the cyclic power law parameters $C_{\mathrm{c}}$ and $n_{\mathrm{c}}$, in which $C_{\mathrm{c}}$ was closure-corrected according to Eq. (4). The transient parameters, $A_{\mathrm{c}}$ and $B_{\mathrm{c}}$, for the cyclic growth were determined using the second cyclic part of test 08 (the mixed test). The value of $\alpha$ was set to correspond to the approximate triaxial state of the $\mathrm{Kb}$-specimen and $\sigma_{0}$ was taken from a tensile test. For a more detailed explanation of the calibration procedure the reader is referred to [2]. Finally, the cyclic threshold parameters were determined using the information shown in Fig. 3. The value of $\Delta K_{\mathrm{th}}$ was chosen to $1.3 \mathrm{MPa} \sqrt{\mathrm{m}}$ (as indicated in test 09 where the $D$ had changed to 0.3 $\mathrm{mm}$ instead of $0.5 \mathrm{~mm}$ ), i.e. on the SIF that test 04 was initiated, and the value of $p$ was determined using an optimisation of tests 04, 05 and 09 . The latter test, 09, was used with the constraint that the damaged zone was measured to $0.3 \mathrm{~mm}$ (see Fig. 3) at the end of the vibration dwell time block. The optimisation process was done by the use of LS-OPT [42] and the complete set of parameters is found in Table 2.

\section{Simulation results}

The result of the simulations performed in this paper must be looked at cautiously. In the calibration procedure only test 09 was available to see how the damaged zone was affected by the vibrational load. This gave a $D$ equal to 0.3 $\mathrm{mm}$ instead of the $0.5 \mathrm{~mm}$ measured for a pure sustained load test, leading to some uncertainties regarding the evolution along the fracture path to the point where $D$ was determined in test 09 . How the vibrational load affects $D$ before this 
point in time therefore remains unknown. The resulting simulations of the tests in Table 1 are therefore to be seen as examples of how the model performs when superimposed vibrational loads/flutter are present.

In Fig. 8a the results from tests 03, 04 and 05 are shown (corresponding to Fig. 2), and the damaged zone evolution for each test is shown in Fig. 8b. Note that test 04 has a starting crack length of $0.5 \mathrm{~mm}$ which gives a higher initial SIF value, thus an increased growth rate of the damaged zone which explains the more rapid growth than for test 03 with $R=0.975$. It can also be seen that test 09 (the mixed test with vibrational load) ends at a damaged zone distance of 0.28 $\mathrm{mm}$ which is in line with the measured one of $0.3 \mathrm{~mm}$ (from the second block of cyclic load). In Fig. 8b it can also be seen that the damaged zone fluctuates somewhat in test 05 and that it drops dramatically in test $04(\Delta K 5 \mathrm{MPa} \sqrt{\mathrm{m}}$ and $3 \mathrm{MPa} \sqrt{\mathrm{m}}$, respectively). This can be explained by the competitiveness of the damage mechanism based growth rate, $\dot{m}$, and the crack growth rate, $\dot{a}_{\mathrm{t}}$ tot. As the damaged zone grows longer, $\dot{a}_{\mathrm{t}}$ tot. is dominating and consumes the zone, and likewise when the damaged zone is short, then the damaged mechanism based growth rate, $\dot{m}$, is dominating and contributes to the build-up of the damaged zone. Consequently, a competitive process takes place between the two, giving the fluctuation like behaviour seen in Fig. 8b. Finally, please note that the model for test 09 is not shown in Fig. 8a, as this result is exactly the same as for test 04 only that it ends at $1.8 \mathrm{~mm}$ as in Fig. 2.

When examining the results in Fig. 8a it can also be seen that the final transients of the tests are not captured by the model, i.e. the crack growth becomes unstable due to SIFs $\left(K_{\max }\right)$ closer to the fracture toughness value. More experimental and modelling work need to be conducted in order to capture this behaviour. 
The remaining $2160 \mathrm{~s}$ tests with and without vibrational load, i.e. tests 06 and 07 respectively, are used to validate the model as no part of these tests have been used in the parameter optimisation process. In parity with Fig. 4, the dwell time crack growth rate is the same with or without a vibrational load as the major load reversals have the overall influence on the crack growth rate. In Fig. 9a the crack growth rates for tests 06,07 and 10 (for comparison purposes) are shown. One load cycle represents the ramp-up, the sustained load and the ramp-down, thus giving an increased growth rate for the $2160 \mathrm{~s}$ dwell time tests compared to the cyclic load test. In Fig. 9b the damaged zone evolution is shown, and it can clearly be seen how the vibrational load is affecting the damaged zone but does not give any major difference in the stabilised crack growth rate. Note that the initial crack length is longer for test 07 than for test 06 (with and without vibration respectively) which in parity with Fig. $8 \mathrm{~b}$ gives a higher growth rate of the damaged zone evolution. It can also be noted that the crack growth rate is slightly overestimated for both tests towards the final crack length. More tests from several different batches are needed in order to receive data for a more comprehensive evaluation.

Finally, in Fig. 10 the crack growth rate per time increment is seen and shows that the $\mathrm{d} a / \mathrm{d} t$ level for the dwell time tests is never exceeded (as mentioned in Section 3.3). Here only the time dependent parts of test 08 and 09 are plotted.

\section{Discussion and conclusions}

The results from the superimposed vibrational load show that no higher crack growth rate than for a dwell time test is achieved, indicating that the crack growth rate lost in dwell time growth is gained by the cyclic vibration growth. The damaged zone length is seen to be reduced by the vibrational loads, see e.g. Fig. 
3 , indicating that care must be taken when conducting simulations of dwell time tests with engine vibrations and flutter. Most studies that involve dwell times have only considered sustained load which is rarely the case in real situations. The incorporation of engine vibrations in the modelling work becomes important in order to predict more accurate crack growth. The effect of the vibrations will (with the model presented) increase as $\Delta K$ increases, as seen in the evolution of the damaged zone in Fig. 8b.

\subsection{Effect on cyclic threshold}

Another important aspect to consider from the dwell time tests with a vibrational load is the determination of threshold values at elevated temperature. Conducting tests with high mean stress, and keeping $K_{\max }$ constant, may cause cyclic loads to show a lower threshold than normally expected if no dwell time damage would be present. This behaviour is clearly seen in Fig. 2 where test 03 with the vibrational load ratio of $R=0.975$ immediately shows an increased crack growth rate. Most likely, the effect is not from cyclic crack growth but rather from the dwell time cracking.

\subsection{Crack branching}

The dwell time crack growth phenomenon used for explaining the embrittling of the grain boundaries is, in a context of high temperature crack growth, accompanied by other effects. As mentioned in Section 4 the crack growth is, especially during the cyclic and vibrational loads, affected by local plastic deformation at the crack tip and by the high temperature the material itself is also affected with changed properties. Some of these effects could have affected the crack branching seen in Fig. 5 and the blunting in Fig. 6. 
From the investigation of the crack paths it was shown that a higher load ratio contributed to longer crack branches. This will most likely be due to that the crack has sought new paths through the grain boundaries, which has not been disturbed by any cyclic load, which might otherwise interfere with the dwell time damage. Consequently, the shorter crack branches for the decreased load ratio (i.e. from one test to another) shows interaction from the cyclic load, giving the crack less mobility for growing when a dwell time is present. Another result from this is that the crack grows in a more straight line than with more dwell time damage. However, a more in depth study is required to confirm these hypotheses.

\section{Summary}

Dwell time crack growth with superimposed vibrational loads has been investigated in this paper. Mechanical experiments have been conducted on surface crack specimens of Inconel 718 at $550^{\circ} \mathrm{C}$ for dwell time tests with and without vibrational loads. Subsequent investigation by SEM was conducted to show the cracking behaviour, and modelling work was performed using the damaged zone concept. By describing how the dwell time interacts with the vibrational loads, larger load reversals, and cyclic threshold, reasonable results were gained with respect to the mechanical tests.

\section{Acknowledgements}

The authors would like to thank Mr. Patrik Härnman, Linköping University, for the laboratory work and the project teams at Linköping University, Siemens Industrial Turbomachinery AB and GKN Aerospace Engine Systems for valuable discussions. This research has been funded by the Swedish Energy Agency, Siemens Industrial Turbomachinery AB, GKN Aerospace Engine Systems, and 
the Royal Institute of Technology through the Swedish research programme TURBO POWER, the support of which is gratefully acknowledged.

\section{References}

[1] U. Krupp. Dynamic embrittlement - time-dependent quasi-brittle intergranular fracture at high temperatures. International Materials Reviews, 50(2):83-97, 2005.

[2] E. Lundström, K. Simonsson, D. Gustafsson, T. Månsson. A load history dependent model for fatigue crack propagation in Inconel 718 under hold time conditions. Engineering Fracture Mechanics, 118:17-30, 2014.

[3] J.P. Pédron, A. Pineau. The effect of microstructure and environment on the crack growth behaviour of Inconel 718 alloy at $650^{\circ} \mathrm{C}$ under fatigue, creep and combined loading Material Science and Engineering, 56(2):143-56, 1982.

[4] J.M. Larsen, T. Nicholas. Load sequence crack growth transients in a superalloy at elevated temperature. Fracture Mechanics: Fourteenth Symposium - Volume II: Testing and Applications, ASTM STP 791, pages II-536-II-552, 1983.

[5] T. Nicholas, T. Weerasooriya. Hold-time effects in elevated temperature fatigue crack propagation. Fracture Mechanics: Seventeenth Volume, ASTM STP 905, pp. 155 - 168, 1986.

[6] T. Weerasooriya. Effect of frequency on fatigue crack growth rate of Inconel 718 at high temperature. Technical report, Air Force Wright Aeronautical Laboratories Report, AFWALTR-87-4038, Wright-Patterson Air Force Base, OH, 1987.

[7] M. Khobaib, N.E. Ashbaugh, G.A. Hartman, T. Weerasooriya, D.C. Maxwell, R.C. Goodman. Research on mechanical properties for engine life prediciton. Technical report, Air Force Wright Aeronautical Laboratories Report, AFWAL-TR-88-4062, Wright-Patterson Air Force Base, OH, 1988.

[8] E. Andrieu, R. Molins, H. Ghonem, A. Pineau. Intergranular crack tip oxidation mechanism in a nickel-based superalloy. Materials Science and Engineering: A, 154(1):21 - 28, 1992.

[9] H. Ghonem, T. Nicholas, A. Pineau. Elevated temperature fatigue crack growth in alloy 718part II: Effects of environmental and material variables. Fatigue \& Fracture of Engineering Materials \& Structures, 16(6):577-590, 1993. 
[10] J.A. Pfaendtner, C.J McMahon Jr. Oxygen-induced intergranular cracking of a Ni-base alloy at elevated temperatures - an example of dynamic embrittlement. Acta Materialia, 49(16):3369 - 3377, 2001.

[11] F.V. Antunes, J.M. Ferreira, C. M. Branco, J. Byrne. Influence of stress state on high temperature fatigue crack growth in Inconel 718. Fatigue \& Fracture of Engineering Materials \& Structures, 24(2):127-135, 2001.

[12] E. Storgärds, K. Simonsson. Crack length evaluation for cyclic and sustained loading at high temperature using potential drop. Experimental Mechanics, 55(3):559-568, 2015.

[13] D.A. Woodford. Gas phase embrittlement and time dependent cracking of nickel based superalloys. Energy Materials: Materials Science and Engineering for Energy Systems, 1(1):59-79, 2006.

[14] D. Bika and C.J. McMahon Jr. A model for dynamic embrittlement. Acta Metallurgica et Materialia, 43(5):1909 - 1916, 1995.

[15] A. Saxena. A model for predicting the effect of frequency on fatigue crack growth behavior at elevated temperature. Fatigue \& Fracture of Engineering Materials \& Structures, 3(3):247$255,1981$.

[16] J.M. Larsen, T. Nicholas. Cumulative-damage modelling of fatigue crack growth in turbine engine materials. Engineering Fracture Mechanics, 22(4):713-730, 1985.

[17] J. Gayda, T.P. Gabb, R.V. Miner. Fatigue crack propagation of nickel-base superalloys at $650^{\circ}$ C. In Low Cycle fatigue, ASTM STP 942, pages 293 - 309, 1988.

[18] S. Kruch, P. Prigent, J.L. Chaboche. A fracture mechanics based fatigue-creep-environment crack growth model for high temperature. International Journal of Pressure Vessels and Piping, 59:141-148, 1994.

[19] F. Gallerneau, S. Kruch, P. Kanouté. A new modelling of crack propagation with fatiguecreep-oxidation interaction under non isothermal loading. In Symposium on Ageing Mechanisms and Control: Part B Monitoring and Management of Gas Turbine Fleets for Extended Life and Reduced Costs, Manchester UK, 8-11 October, 2001.

[20] E Storgärds, , K. Simonsson, S. Sjöström, D. Gustafsson, T. Månsson. Modeling of crack growth with dwell time for aero-engine spectra loadings in a Ni-based superalloy. Journal of Engineering for Gas Turbines and Power, 138(1):012501-012501-6, 2015.

[21] S. Ponnelle, B. Brethes, A. Pineau. High temperature fatigue crack growth rate in Inconel 
718: Dwell effect annihilations. European Structural Integrity Society, 29:257 - 266, 2002.

[22] T. Nicholas, G.K. Haritos, R.L. Hastie Jr., K. Harms. The effect of overloads on sustainedload crack growth in a nickel-base superalloy: part II-experiments. Theoretical and Applied Fracture Mechanics, 16:51-62, 1991.

[23] D. Gustafsson, E. Lundström. High temperature fatigue crack growth behaviour of Inconel 718 under hold time and overload conditions. International Journal of Fatigue, 48:178 186, 2013.

[24] J. Saarimäki, J. Moverare, R. Eriksson, S. Johansson. Influence of overloads on dwell time fatigue crack growth in Inconel 718. Materials Science and Engineering: A, 612:398 - 405, 2014.

[25] E Storgärds, J. Saarimäki, K. Simonsson, S. Sjöström, D. Gustafsson, T. Månsson, J. Moverare. Scatter in dwell time cracking for a Ni-based superalloy in combination with overloads. Journal of Engineering for Gas Turbines and Power, 138(1):012502-012502-7, 2015.

[26] R.J.H. Wanhill. Significance of dwell cracking for IN718 turbine discs. International Journal of Fatigue, 24(5):545 - 555, 2002.

[27] E. Lundström, K. Simonsson, T. Månsson, D. Gustafsson. Modelling of fatigue crack growth in Inconel 718 under hold time conditions - application to a flight spectrum. Advanced Materials Research, 891-892:759-764, 2014.

[28] L. Jacobsson, C. Persson, S. Melin. Thermo-mechanical fatigue crack propagation experiments in Inconel 718. International Journal of Fatigue, 31:1318-1326, 2009.

[29] J.J. Moverare and D. Gustafsson. Hold-time effect on the thermo-mechanical fatigue crack growth behaviour of Inconel 718. Materials Science and Engineering: A, 528(29 - 30):8660 $-8670,2011$.

[30] V.M. Barker, W.S. Johnson, B.S. Adair, S.D. Antolovich. Load and temperature interaction modeling of fatigue crack growth in a ni-base superalloy. International Journal of Fatigue, 52:91-105, 2013.

[31] E Storgärds, K. Simonsson, S. Sjöström, J. Moverare. Thermomechanical fatigue crack growth modeling in a Ni-based superalloy subjected to sustained load. Journal of Engineering for Gas Turbines and Power, 138(1):012503-012503-7, 2015.

[32] N.E. Ashbaugh, M. Khobaib, T. Weerasooriya, G.A. Hartman, A.M. Rajendran, D.C. Maxwell, R.C. Goodman. Advances in the study of the mechanical behavior of materials. 
Technical report, Air Force Wright Aeronautical Laboratories Report, AFWAL-TR-85-4124, Wright-Patterson Air Force Base, OH, 1985.

[33] J. Gallagher, T. Nicholas, A. Gunderson, J. Ruschau, P. Miedlar, A. Hutson, G. Hardy, D. Walls, C. Annis, R. de Laneuville, P. Gravett, E. Hindle, M. Szolwinski, R. Naik, B. Cowles, J. Adamson, R. Pettit, K. Kersey, M. Marotta, D. Corbly, R. Van Stone, D. Slavik, M. Hartle, R. McClain, K. Wright, H. Merrick, D. Cameron, Y. Lenets, J. Hartman, K. Cornet, D. Wildman, C. Weeks, P. Bastnagel, T. Cook, A. Chaterjee, S. Hudak, K. Chan, C. McClung, D. Davidson, G. Chell, Der Lee Y., T. Farris, A. Grandt, P. Golden, H. Murthy, B. Bartha, J. Matlik, D. Garcia, E. Perez-Ruberté, P. Rajeev, A. Kallmeyer, P. Kurath, G. Glinka, B. Lawless. Advanced high cycle fatigue (HCF) life assurance methodologies. Technical report, Materials and Manufacturing Directorate Air Force Research Laboratory Air Force Materiel Command, AFRL-ML-WP-TR-2005-4102, Wright-Patterson Air Force Base, OH 45433-7750, 2005.

[34] D. Gustafsson, E. Lundström, K. Simonsson. Modelling of high temperature fatigue crack growth in Inconel 718 under hold time conditions. International Journal of Fatigue, 52:124 $-130,2013$.

[35] ASTM E647-08, Standard Test Method for Measurement of Fatigue Crack Growth Rates, ASTM International, West Conshohocken, PA, 2008.

[36] J.C. Newman, Jr., I.S. Raju. Stress-intensity factor equations for cracks in three-dimensional finite bodies subjected to tension and bending loads. Technical report, NASA Technical Memorandum 85793, 1984.

[37] E. Storgärds. High Temperature Fatigue Crack Growth in a Ni-based Superalloy: Modelling Including the Interaction of Dwell Times. Linköping University, ISBN: 978-91-7519-0341, doi: http://dx.doi.org/10.3384/diss.diva-121012, 2015.

[38] A. Diboine, A. Pineau. Creep crack initiation and growth in Inconel 718 alloy at $650^{\circ} \mathrm{C}$. Fatigue \& Fracture of Engineering Materials \& Structures, 10(2):141-151, 1987.

[39] I. Gutierrez-Urrutia, S. Zaefferer, D. Raabe. Electron channeling contrast imaging of twins and dislocations in twinning-induced plasticity steels under controlled diffraction conditions in a scanning electron microscope. Scripta Materialia, 61(7):737 - 740, 2009.

[40] NASGRO manual 7.0, SwRI.

[41] J.C. Newman Jr. A crack opening stress equation for fatigue crack growth. International 
Journal of Fracture, 24:R131-R135, 1984.

[42] N. Stander, W. Roux, T. Goel, T. Eggleston, K. Craig, LS-OPT User's manual, Version 4.2, Livermore Software Technology Corporation, Livermore, CA (2011). 


\begin{tabular}{|ll|}
\hline Nomenclature & \\
$A$ & fitting parameter \\
$B$ & fitting parameter \\
$C$ & power law constant \\
$D$ & damaged zone length \\
DCPD & direct current potential drop \\
DE & dynamic embrittlement \\
EDM & electro discharge machining \\
$K$ & stress intensity factor \\
$S$ & scale function \\
SAGBO & stress accelerated grain boundary oxidation \\
SIF & stress intensity factor \\
$a$ & crack length \\
$\dot{a}$ & crack growth rate \\
$\dot{m}$ & dime dependent value \\
$n$ & stress \\
$\alpha$ & power law constant \\
$\Delta K$ & constraint parameter \\
c & stress intensity factor range \\
& \\
\hline &
\end{tabular}




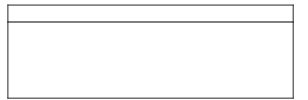

(a)

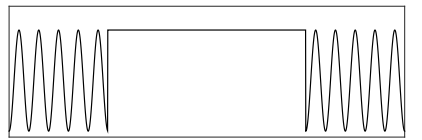

(e)

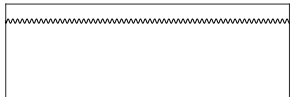

(b)

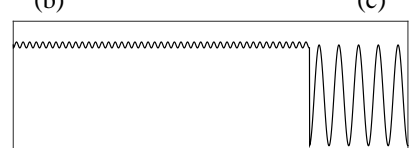

(f)
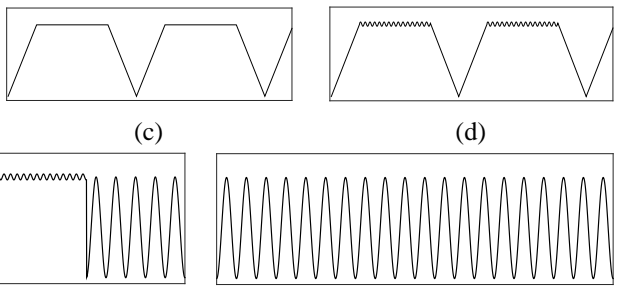

(g)

Figure 1: Schematic illustrations of the different test types plotted as load vs. time. (a) Dwell, (b) dwell + vibration, (c) $2160 \mathrm{~s}$, (d) $2160 \mathrm{~s}+$ vibration, (e) mixed, (f) mixed + vibration and (g) cyclic. 
Table 1: Performed tests with data for each test type, block 1 (block 2, block 3).

\begin{tabular}{lllllllll}
\hline Test no. & Test type & $R$ & $\Delta K$ at $2.5 \mathrm{~mm}[\mathrm{MPa} \sqrt{\mathrm{m}}]$ & $f[\mathrm{~Hz}]$ & $\sigma_{\max }[\mathrm{MPa}]$ & $\sigma_{\min }[\mathrm{MPa}]$ & $a_{\text {start }}[\mathrm{mm}]$ & $a_{\text {final }}[\mathrm{mm}]$ \\
\hline 01 & Dwell & - & - & - & 650 & - & 0.49 & 2.50 \\
02 & Dwell & - & - & - & 650 & - & 0.49 & 2.50 \\
03 & Dwell + vib. & 0.975 & 1 & 10 & 658 & 642 & 0.40 & 2.60 \\
04 & Dwell + vib. & 0.928 & 3 & 10 & 674 & 626 & 0.50 & 2.60 \\
05 & Dwell + vib. & 0.880 & 5 & 10 & 690 & 610 & 0.40 & 2.58 \\
06 & $2160 \mathrm{~s}$ & 0.05 & - & - & 650 & 32.5 & 0.35 & 2.46 \\
07 & $2160 \mathrm{~s}+$ vib. & 0.05 & 3 & 10 & 650 & 32.5 & 0.49 & 2.80 \\
08 & Mixed & $0.05(-, 0.05)$ & $-(-,-)$ & $0.05(-, 0.05)$ & $650(650,650)$ & $32.5(-, 32.5)$ & $0.20(0.53,1.80)$ & 2.60 \\
09 & Mixed + vib. & $0.928(0.05)$ & $3(-)$ & $10(0.05)$ & $674(650)$ & $626(32.5)$ & $0.50(1.80)$ & 2.60 \\
10 & Cyclic & 0.05 & - & 0.05 & 650 & 32.5 & 0.23 & 2.57 \\
\hline
\end{tabular}




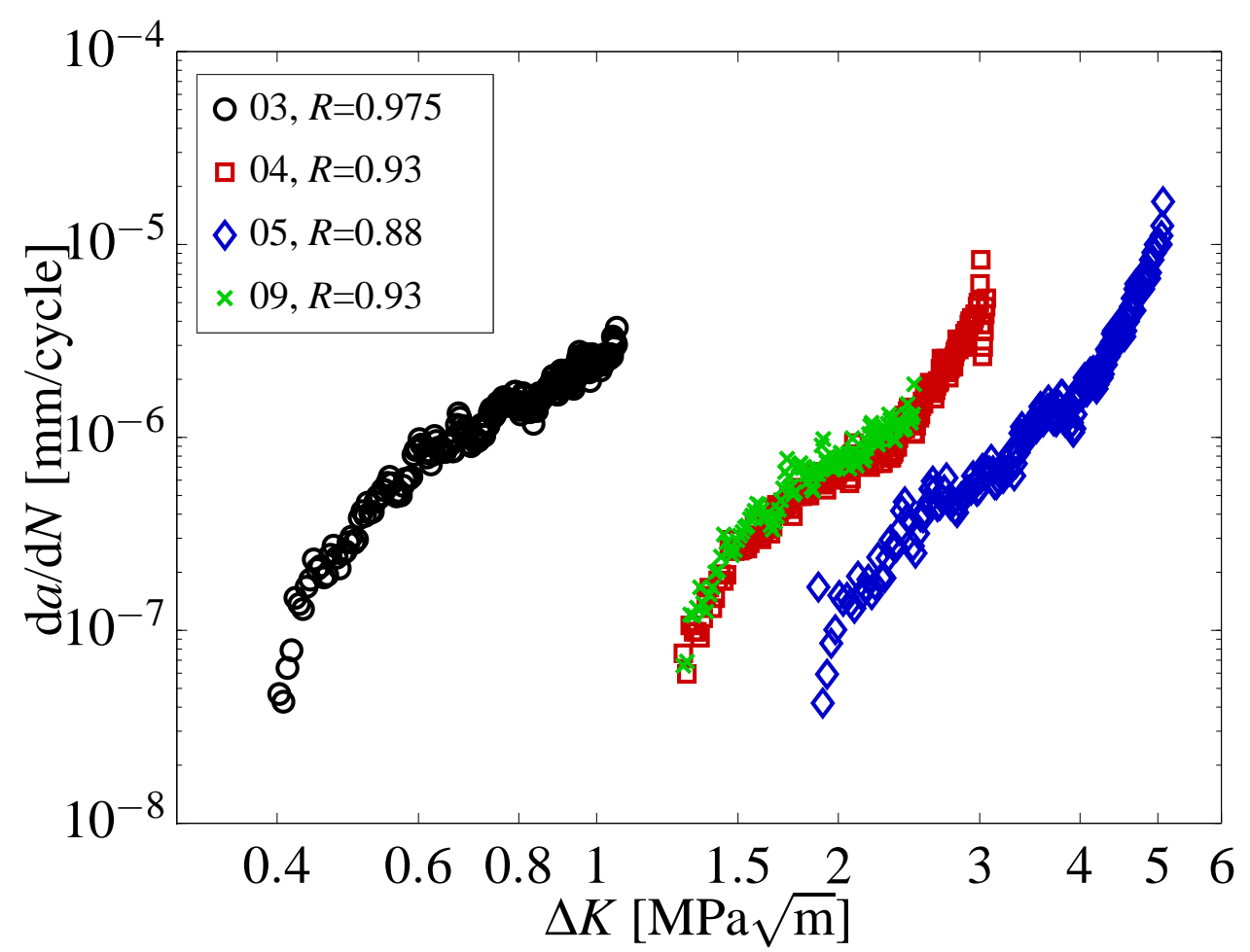

Figure 2: Crack growth rate for the dwell time tests with superimposed vibrational loads. 


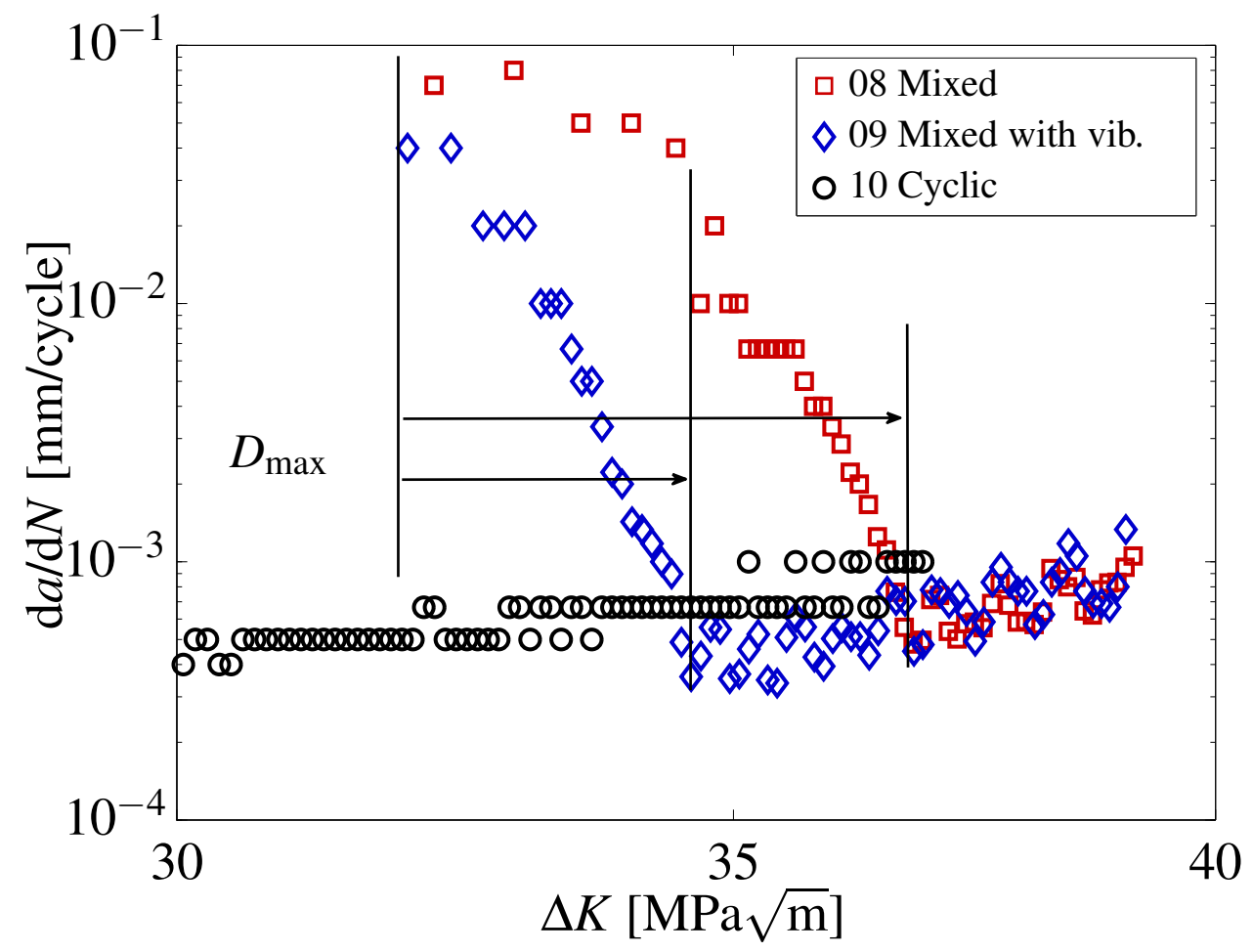

Figure 3: Crack growth rate for all tests with time dependent damage. 


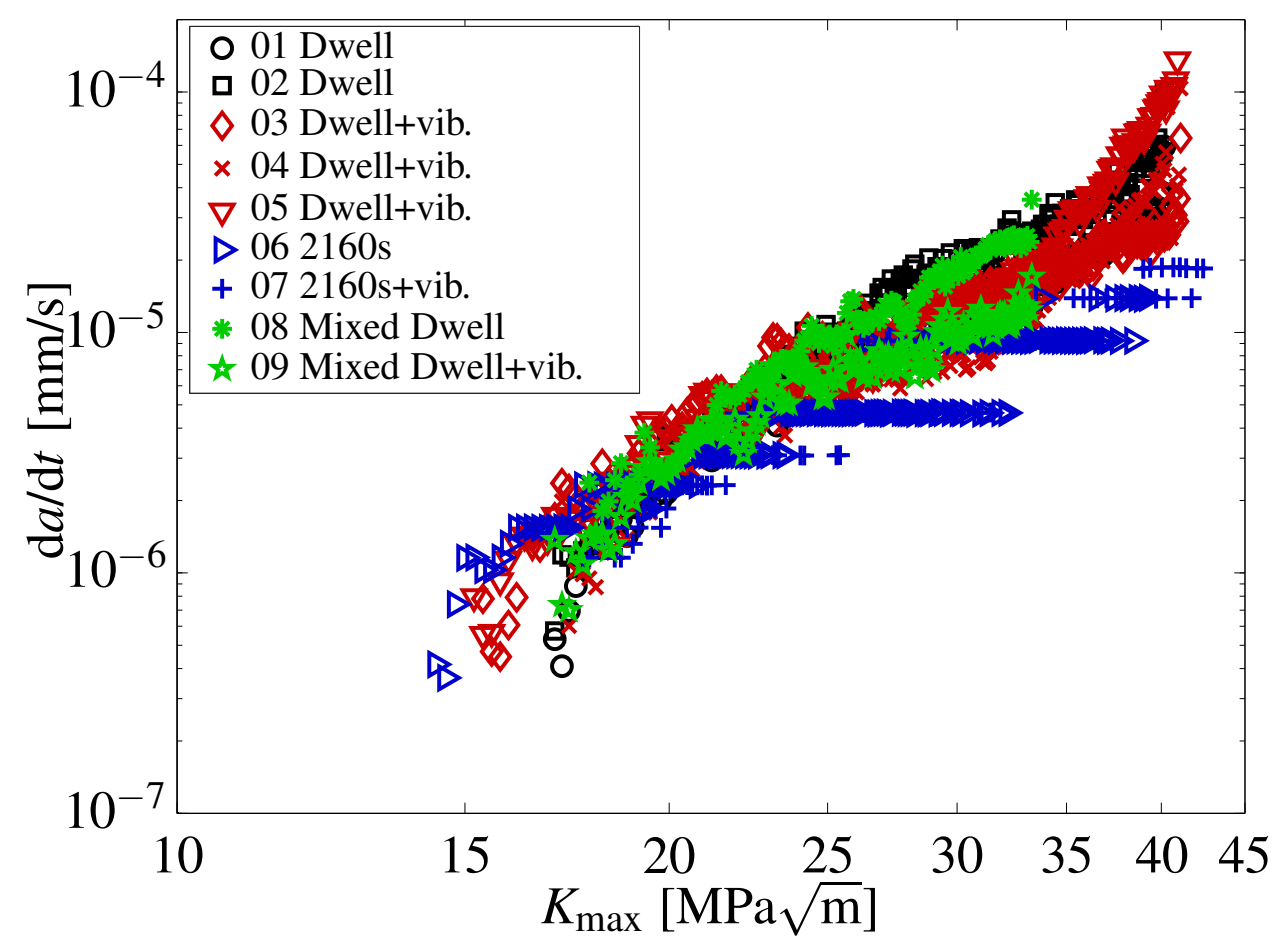

Figure 4: Crack growth rate for all tests with time dependent damage. 


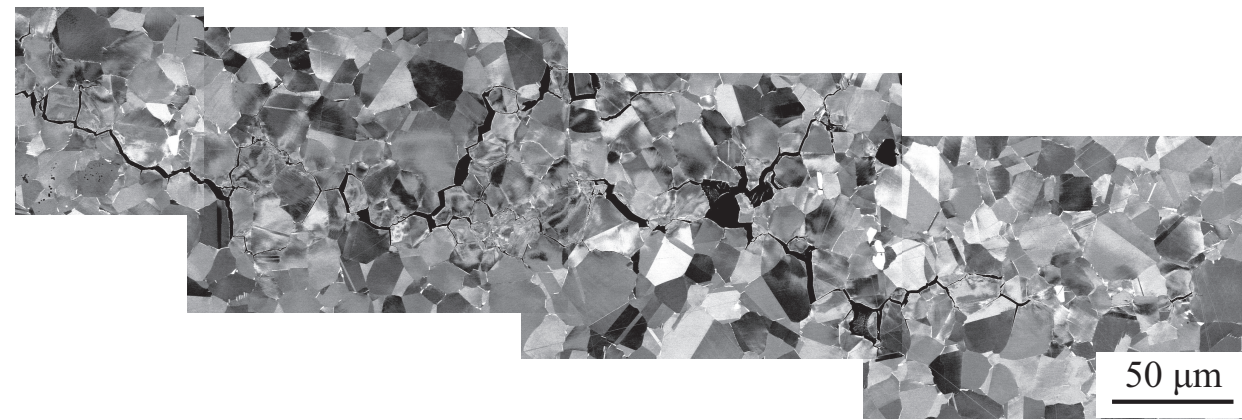

(a)

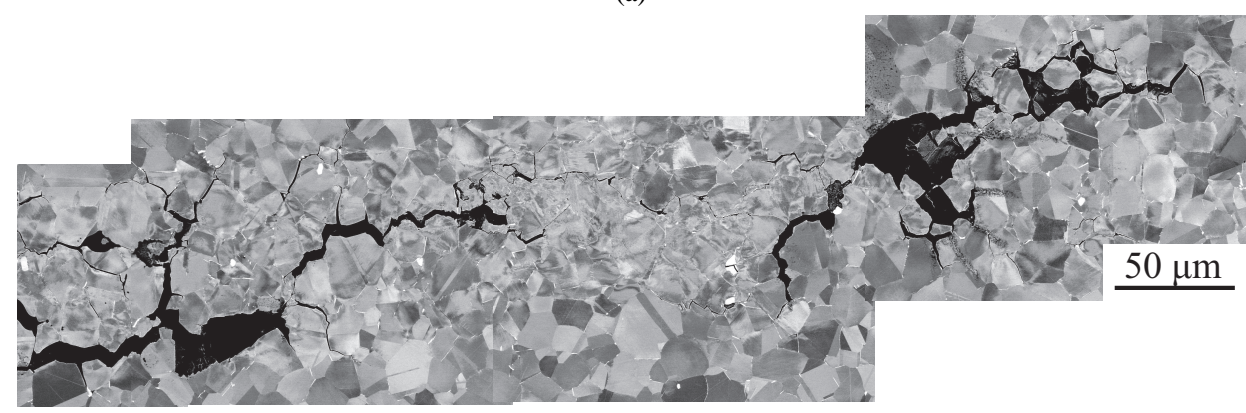

(b)

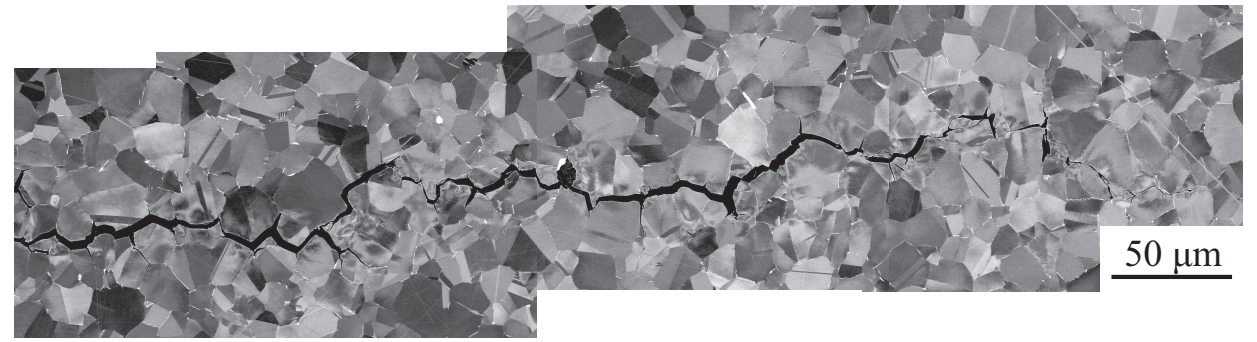

(c)

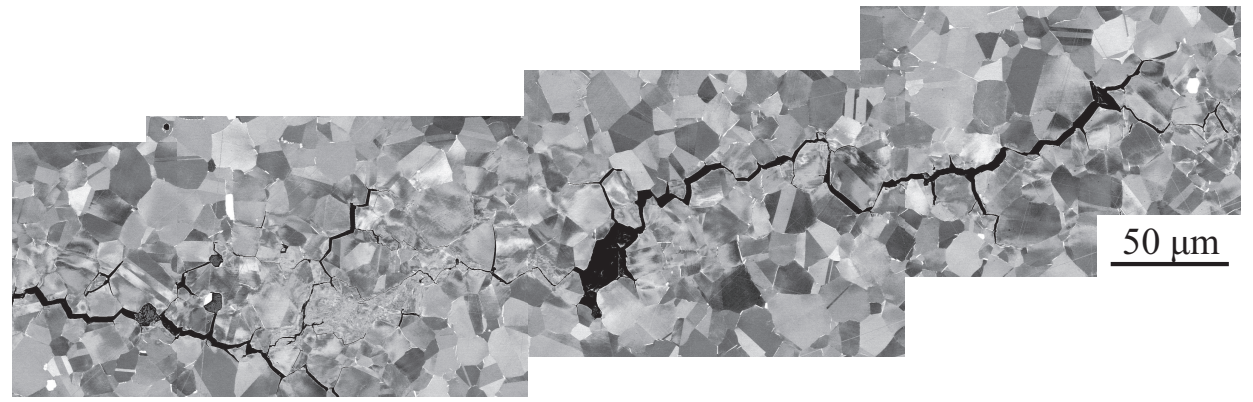

(d)

Figure 5: Crack paths for different tests. (a) Test 03, dwell time with a vibration load of $R=0.975$, (b) test 04 , dwell time with a vibration load of $R=0.93$, (c) test 05 , dwell time with a vibration load of $R=0.88$ and (d) test 07 with $2160 \mathrm{~s}$ dwell with a vibration load of $R=0.93$. 


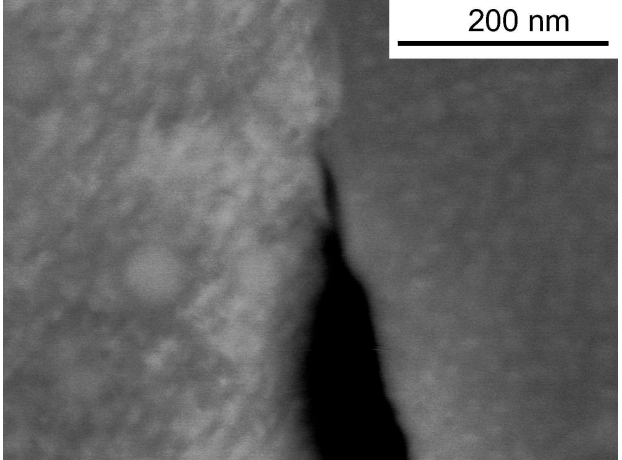

(a)

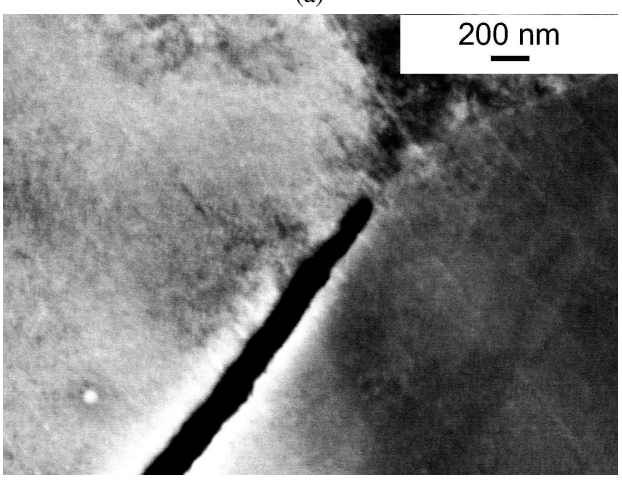

(c)

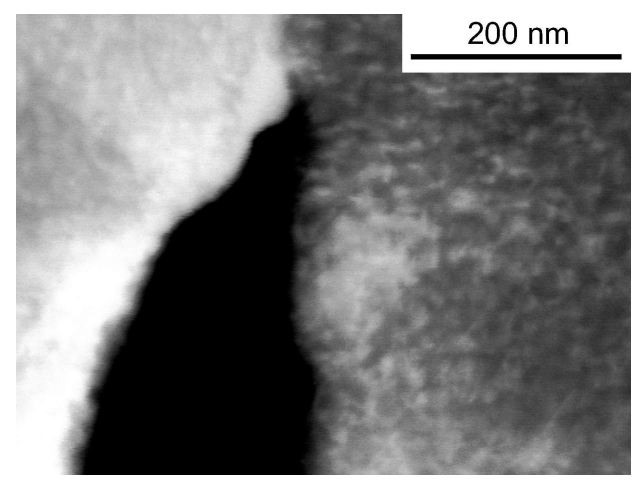

(b)

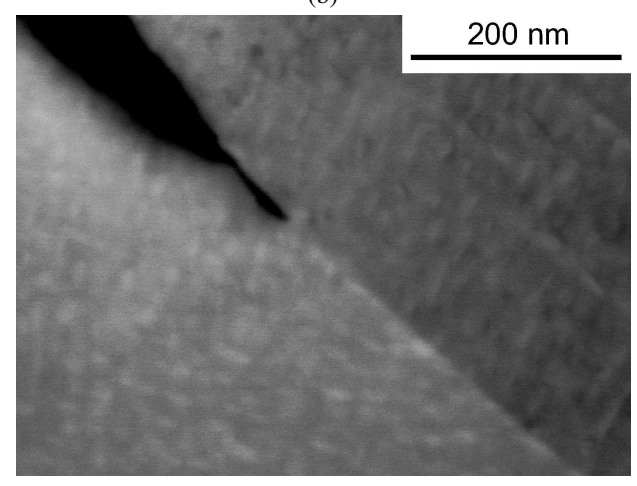

(d)

Figure 6: Crack tips for different tests. (a) Test 03, dwell time with a vibration load of $R=0.975$, (b) test 04 , dwell time with a vibration load of $R=0.93$, (c) test 05 , dwell time with a vibration load of $R=0.88$ and (d) test $07,2160 \mathrm{~s}$ dwell with a vibration load of $R=0.93$. 


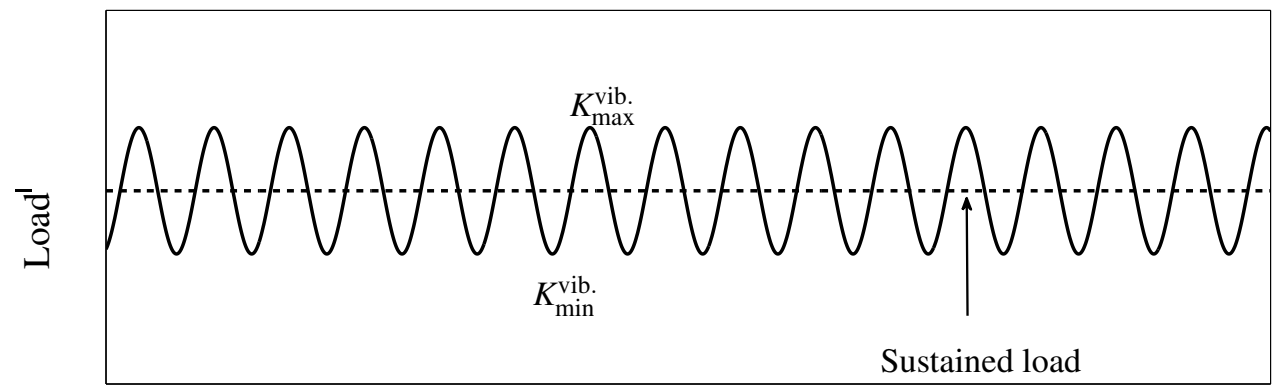

Time

Figure 7: SIF values used for defining the vibrational load. 
Table 2: Model parameters, units in $\mathrm{MPa}, \mathrm{MPa} \sqrt{\mathrm{m}}, \mathrm{m} / \mathrm{s}$ and $\mathrm{m} /$ cycle; $D_{\max }$ in $\mathrm{mm}$.

\begin{tabular}{llllllllllll}
\hline$C_{0 \mathrm{t}}$ & $n_{\mathrm{t}}$ & $C_{\mathrm{c}}$ & $n_{\mathrm{c}}$ & $B_{\mathrm{t}}$ & $A_{\mathrm{c}}$ & $B_{\mathrm{c}}$ & $D_{\max }$ & $\alpha$ & $\sigma_{0}$ & $p$ & $\Delta K_{\mathrm{th}}$ \\
\hline $3.6 \times 10^{-14}$ & 3.8 & $3.0 \times 10^{-10}$ & 2.3 & 4.8 & 215 & 2.1 & 0.5 & 2.5 & 1100 & 3.0 & 1.3 \\
\hline
\end{tabular}




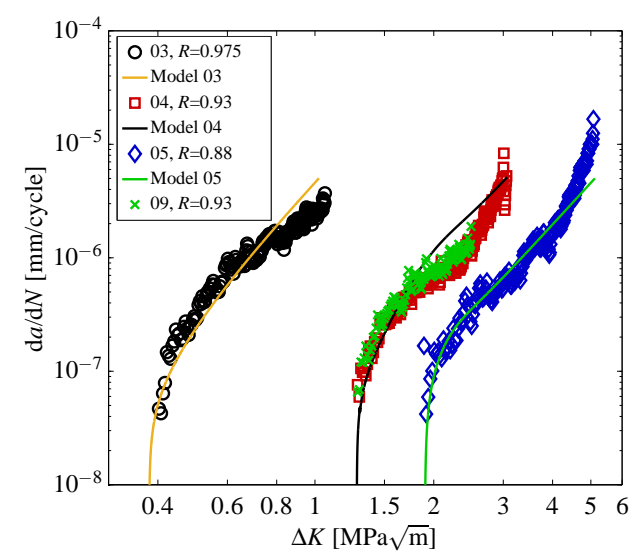

(a)

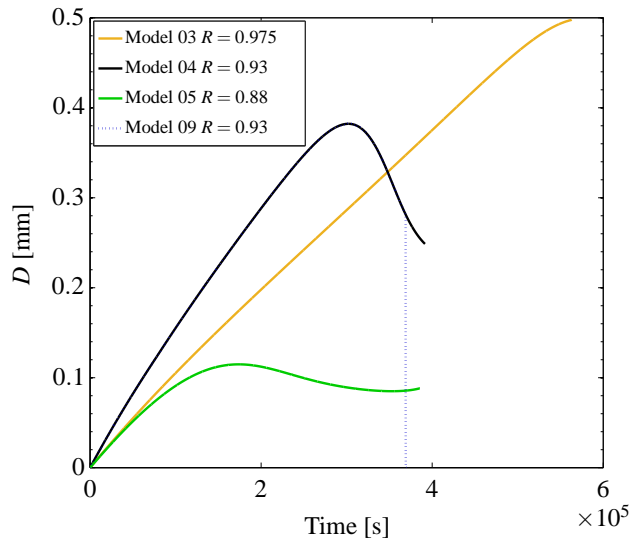

(b)

Figure 8: Simulation results for the dwell time test with a superimposed vibrational load. (a) Crack growth rate as function of SIF and (b) damaged zone evolution. 


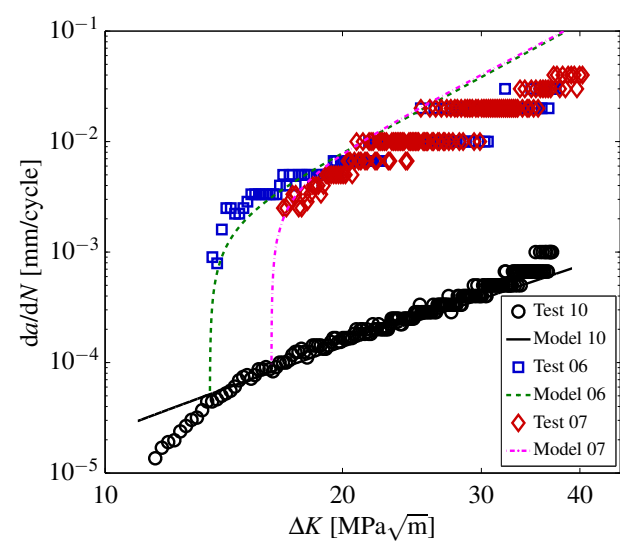

(a)

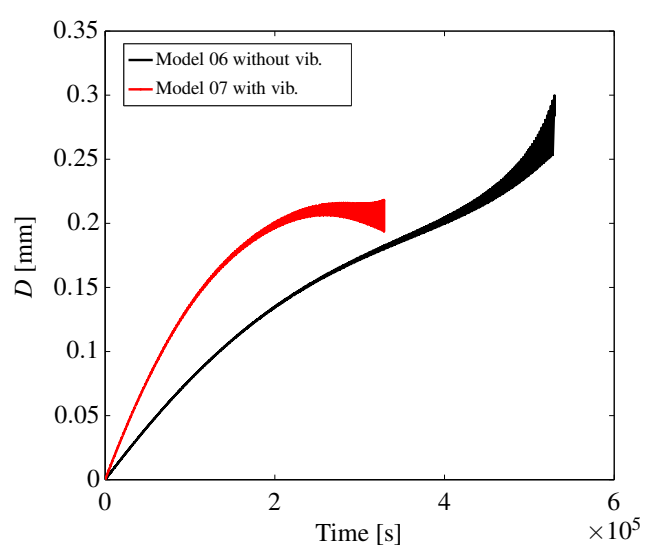

(b)

Figure 9: Simulation results for the 2160 s tests. (a) Crack growth rate as function of SIF and (b) damaged zone evolution. 


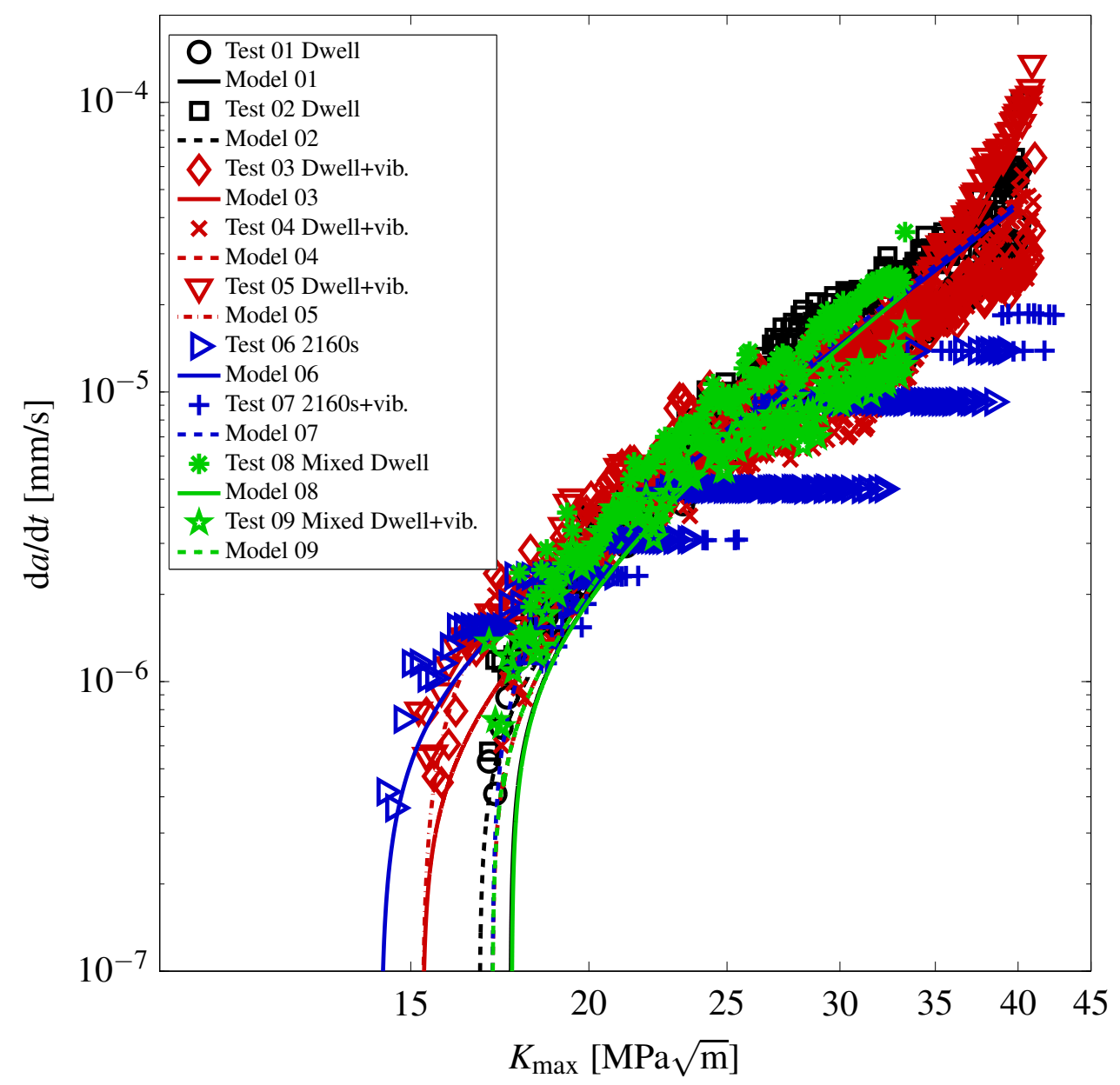

Figure 10: Time dependent crack growth rate for all tests in Table 1. 